\title{
Effect of intraduodenal fat on lower oesophageal sphincter function and gastro-oesophageal reflux
}

\author{
R H Holloway, E Lyrenas, A Ireland, J Dent
}

\begin{abstract}
Background and Aims-Fatty foods are commonly reported to aggravate gastrooesophageal reflux symptoms. In this study the hypothesis that fat provokes reflux by stimulating transient lower oesophageal sphincter relaxations via small intestinal receptors was investigated.

Methods-In 12 healthy volunteers and 11 patients with reflux oesophagitis, oesophageal motility and pH were measured over 30 minute periods during which saline or fat $(10 \%$ Intralipid) were infused in random order into the duodenum. The infusion periods were separated by a 30 minute washout. The stomach was loaded with $200 \mathrm{ml} \mathrm{10 \%}$ dextrose, maintained by an intragastric infusion.

Results-Fat decreased basal LOS pressure from 16.9 (SEM 2.1) to 12.4 (SEM 1.5) mm $\mathrm{Hg}$ in normal subjects but had no effect in patients with oesophagitis (18.8 (SEM 4.3) v 18.2 (SEM 3.0) $\mathrm{mm} \mathrm{Hg}$ ). During saline infusion, the rates of transient lower oesophageal sphincter relaxations and reflux episodes were greater in patients (4.5 (interquartile range $2-11) / 30$ min and 5 (2-14)/30 min respectively) than in controls $(3(2-4) / 30 \mathrm{~min}$ and $3(2-3 \cdot 5) / 30$ min respectively). Fat increased the rate of reflux episodes in the reflux patients to 6.5 (3-25)/30 min. This effect was due to an increase in the incidence of reflux during transient LOS relaxations $(65 \%$ v 91\%), the rate of transient relaxations remaining unchanged.

Conclusions-Instillation of fat directly into the duodenum aggravates reflux in patients with reflux disease, by increasing the proportion of transient LOS relaxations accompanied by reflux. (Gut 1997; 40: 449-453)
\end{abstract}

Keywords: oesophagus, oesophagogastric junction, reflux oesophagitis.

Fatty foods are commonly reported to aggravate symptoms of gastro-oesophageal reflux. ${ }^{1}$ Objective evaluation of this phenomenon, however, has been limited. Ambulatory oesophageal $\mathrm{pH}$ monitoring studies suggest that in normal subjects, but not in patients with reflux disease, fatty foods cause more reflux than do equicaloric quantities of low fat foods. ${ }^{2}$
It has been suggested that fat aggravates reflux through its effect on basal lower oesophageal sphincter (LOS) pressure. Ingestion of fat decreases basal LOS pressure ${ }^{34}$ and this effect is more pronounced with direct instillation of fat into the duodenum. Most postprandial reflux episodes, however, occur during transient LOS relaxations ${ }^{5-7}$ rather than low steady state basal LOS pressure. The aim of this study, therefore, was to investigate the hypothesis that fatty foods aggravate reflux by increasing the rate of transient LOS relaxations through stimulation of small intestinal fat receptors.

\section{Methods}

SUBJECTS

We studied 12 healthy volunteers (five men, seven women, aged 18-35, median 26 years). All were free of reflux symptoms and had no history of upper gastrointestinal disease. Studies were also performed on 11 patients $(10$ men, one woman, aged 44-76, median 58 years) with erosive or ulcerative oesophagitis which had been shown endoscopically within six months of the study. All subjects gave written informed consent, and the study was approved by the Human Ethics Committee of the Royal Adelaide Hospital.

\section{RECORDING TECHNIOUES}

Oesophageal manometry was performed with a multilumen assembly. A sleeve sensor monitored LOS pressure. ${ }^{8}$ Side holes at the distal margin of the sleeve and $10 \mathrm{~cm}$ more distally monitored gastric pressure while additional side holes monitored pressure in the oesophagus, at 2,6 , and $10 \mathrm{~cm}$ above the LOS. A pharyngeal side hole monitored swallowing. The sleeve and gastric lumens were perfused at $0.5 \mathrm{ml} / \mathrm{min}$ by a pneumohydraulic capillary infusion system. The oesophageal and pharyngeal lumens were perfused at $0.13 \mathrm{ml} / \mathrm{min}$ to minimise the effects of perfusion on swallowing and oesophageal acid clearance yet yield reliable recognition of the occurrence of motor events.

Oesophageal $\mathrm{pH}$ was monitored $5 \mathrm{~cm}$ above the proximal margin of the LOS with a miniature glass intraluminal $\mathrm{pH}$ electrode (radiometer GK2801C or microelectrodes MI506). The electrodes were calibrated in buffers of $\mathrm{pH} 2$ and 7 before and after each study. 
Correction for electrode calibration drifts was made on the assumption that the drift was linear throughout the study (in all cases any drifts were less than $0.4 \mathrm{pH}$ units). Signals from the pressure transducers and $\mathrm{pH}$ electrodes were processed and recorded on a multichannel recorder at a paper speed of $100 \mathrm{~mm} / \mathrm{min}$.

Solutions were infused into the stomach via an infusion port $5 \mathrm{~cm}$ distal to the sleeve sensor, and into the duodenum via an infusion port $20 \mathrm{~cm}$ beyond the distal end of the sleeve. Correct position of the infusion port in the duodenum was ensured by measuring transmucosal potential difference (TMPD) ${ }^{9}$ with additional side holes at the level of the duodenal infusion port and $5 \mathrm{~cm}$ more orad. The position of the duodenal infusion port was monitored throughout the study using TMPD.

STUDY PROTOCOL

The subjects were studied after an overnight fast. Histamine $\mathrm{H}_{2}$ receptor antagonists were stopped at least 48 hours before the study (no patient was taking a proton pump inhibitor), and drugs that could affect oesophageal motility were stopped at least 24 hours before the study. Smoking was not permitted on the day of the study. The manometric assembly and $\mathrm{pH}$ electrode were passed via the nose. After the manometric assembly had been correctly positioned with the sleeve sensor straddling the LOS and the infusion port in the duodenum, the subjects were positioned lying on their right side and allowed to adapt to the assembly for 15 minutes. The stomach was then loaded with $200 \mathrm{ml} 10 \%$ dextrose at $\mathrm{pH} 2$ via the manometric assembly. Normal saline or a fat solution (Intralipid 10\%, KABI Vitrum, Stockholm) were then infused into the duodenum at $1 \mathrm{ml} / \mathrm{min}$ during two 30 minute periods which were separated by a 30 minute washout period with no duodenal infusion. The rate of duodenal infusion was selected because it is within the estimated rate of delivery of calories to the duodenum during gastric emptying of a meal ${ }^{1011}$ and reliably produces alterations in gastric and pyloric motility. ${ }^{12}$ The order of saline and fat infusion was randomised among the subjects. In an attempt to maintain an equivalent intragastric volume during the saline and intraduodenal fat phases of the study, $10 \%$ dextrose solution at $\mathrm{pH} 2$ was infused intragastrically at $6 \mathrm{ml} / \mathrm{min}$ during the intraduodenal infusion of saline and during the washout period to compensate for the estimated gastric emptying of the dextrose solution. ${ }^{10}$ No dextrose was infused during the intraduodenal infusion of Intralipid because gastric emptying virtually stops during this stimulus. ${ }^{13}$

\section{DATA ANALYSIS}

The duodenal infusions were coded on the chart recordings to blind the analyst to the nature of the infusion. The $\mathrm{pH}$ recording was analysed manually. Reflux episodes were defined as either an abrupt fall in oesophageal $\mathrm{pH}$ below 4 for at least four seconds or, if oesophageal $\mathrm{pH}$ was already below 4 , a further abrupt drop of at least one $\mathrm{pH}$ unit for at least four seconds. ${ }^{6}$

Basal end expiratory LOS pressure was referenced to intragastric pressure and determined at one minute intervals by taking a visual mean of the tracing. Mean values were calculated for each 30 minute period. The onset of the abrupt drop in oesophageal $\mathrm{pH}$ was used as the reference time for analysis of the motor events associated with reflux. For all reflux episodes the following variables were measured $^{6}$ : (1) LOS pressure at time of onset of the $\mathrm{pH}$ drop or, if straining obscured this measurement, in the five seconds preceding the $\mathrm{pH}$ drop, (2) basal LOS pressure 30 seconds before the $\mathrm{pH}$ drop, (3) the pattern of LOS pressure associated with the reflux episode, (4) occurrence of swallowing, (5) the pattern of oesophageal body motility associated with onset of the $\mathrm{pH}$ drop, (6) the occurrence of a strain in the five seconds before the $\mathrm{pH}$ drop, and (7) the occurrence of an oesophageal common cavity. Peristalsis was judged to be successful if a propagated pressure wave of at least $10 \mathrm{~mm} \mathrm{Hg}$ occurred at all oesophageal recording points.

Transient LOS relaxation was defined as an abrupt ( $\geq 1 \mathrm{~mm} \mathrm{Hg} / \mathrm{s}$ ) fall in LOS pressure of $>3 \mathrm{~mm} \mathrm{Hg}$ to a level $\leq 2 \mathrm{~mm} \mathrm{Hg}$ above intragastric pressure that was not associated with swallowing within five seconds before the onset of LOS relaxation until maximal relaxation had been achieved and which lasted for at least five seconds. ${ }^{14}$ Lower oesophageal sphincter relaxations with onset associated with a swallow within five seconds before its onset until maximal relaxation had been achieved were judged to be induced by swallow. Persistently absent basal LOS pressure was scored as present when LOS pressure was $\leq 2 \mathrm{~mm} \mathrm{Hg}$ for $>30$ seconds. An abdominal strain was defined as a sharp and simultaneous increase in gastric and oesophageal pressure, greater than twice the normal inspiratory increase in intragastric pressure. Deep inspiration was identified as an inspiratory pressure drop that was present in both oesophageal pressure recordings and was at least twice the normal inspiratory pressure excursion. Straining was judged to be the principal mechanism of reflux when the onset of an acid $\mathrm{pH}$ deflection occurred during a strain when there was detectable $(>2 \mathrm{~mm} \mathrm{Hg}$ ) LOS pressure, and as a possible cofactor when LOS pressure at the time of reflux was $\leq 2 \mathrm{~mm} \mathrm{Hg}$.

Statistical analysis of basal LOS pressure was performed by analysis of variance (ANOVA). The rates of transient LOS relaxations and reflux episodes were analysed with non-parametric tests. The proportions of transient LOS relaxations associated with reflux analysed by $\chi^{2}$ test and Wilcoxon signed rank test. A p value of $<0.05$ was accepted as indicating significance.

\section{Results}

BASAL LOS PRESSURE

During control saline infusions, basal LOS pressure in the patients with reflux disease was 


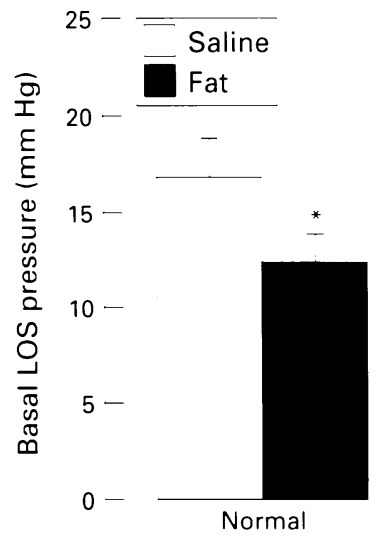

Figure 1: Effect of intraduodenal fat on basal lower oesophageal sphincter (LOS) pressure. Data expressed as mean $(S E M) .{ }^{*} p<0.05 \mathrm{v}$ saline.

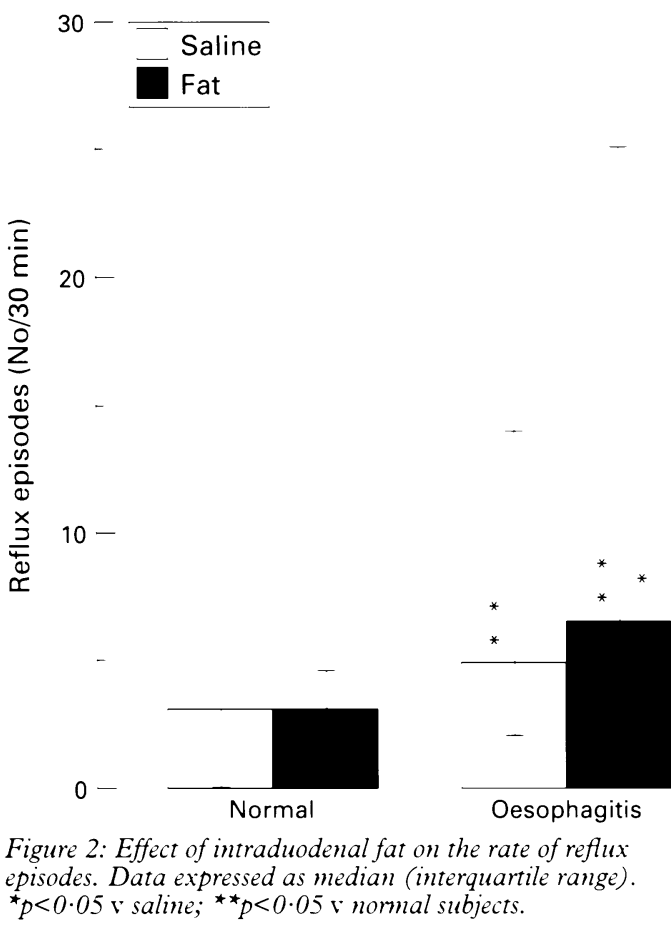

similar to that in the normal subjects. In the normal subjects, intraduodenal fat reduced basal LOS pressure from $16.9($ SEM $2 \cdot 1) \mathrm{mm}$ $\mathrm{Hg}$ to 12.4 (SEM 1.5) $\mathrm{mm} \mathrm{Hg}(\mathrm{p}<0.05)$, whereas in the patients basal LOS pressure was unchanged (Fig 1).

GASTRO-OESOPHAGEAL REFLLX

The patients with reflux disease exhibited a significantly higher rate of reflux episodes than did the normal subjects during both the saline and fat infusions (Fig 2). In the patients with reflux disease, intraduodenal fat increased the rate of reflux episodes from a median of 5 (interquartile range $2-14) / 30 \mathrm{~min}$ to 6.5 $(3-25) / 30 \mathrm{~min}(\mathrm{p}<0.05)$, but had no effect on the rate of reflux episodes in the normal subjects. Most reflux episodes occurred during transient LOS relaxations (Fig 3). However, intraduodenal fat had no effect on the patterns of LOS pressure associated with reflux episodes.
TRANSIENT LOS RELAXATIONS

Patients with reflux disease manifested a significantly higher rate of transient LOS relaxations than did the normal subjects during both saline $(4.5(2-11) / 30 \mathrm{~min} \approx 3(2-4) / 30$ $\min ; \mathrm{p}<0.005)$ and fat $(5.5(2-16) / 30 \mathrm{~min} i 3$ $(2-3 \cdot 5) / 30 \mathrm{~min} ; \mathrm{p}<0.005)$ infusions (Fig 4). However, intraduodenal fat had no effect on the rate of transient LOS relaxations in either group. During saline infusion, patients with reflux disease also manifested a similar proportion of transient LOS relaxations accompanied by reflux to normal subjects $(65 \% v$ $52 \%$; Fig 5 ). Fat increased the number of transient LOS relaxations accompanied by reflux in patients with reflux disease from $65 \%$ to $91 \%(\mathrm{p}<0.05)$ but had no effect in normal subjects.
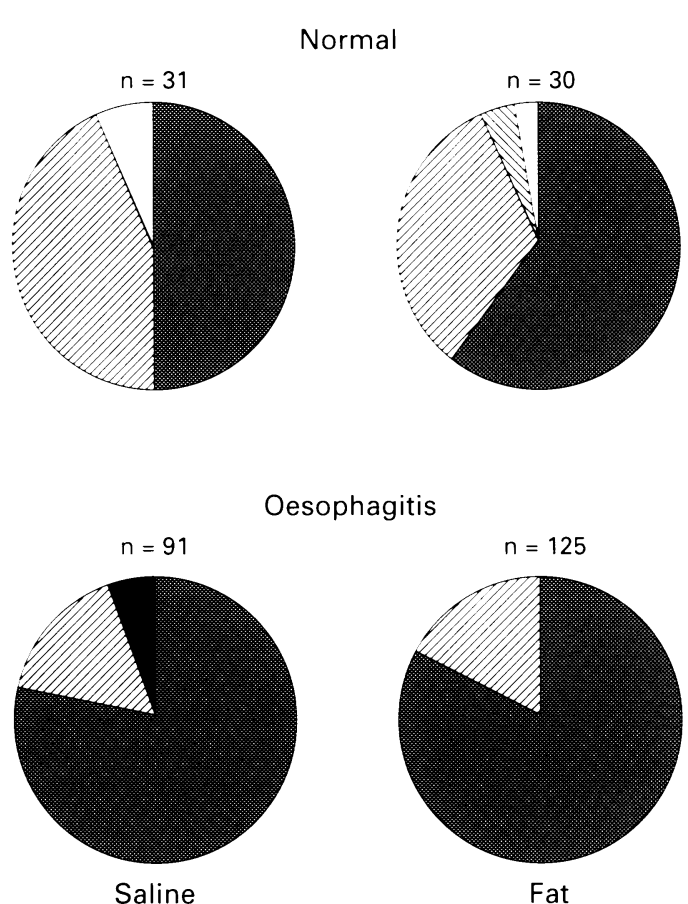

Figure 3: Effect of intraduodenal fat on the mechanisms of reflux. No significant differences were seen between intraduodenal saline and fat. 圆 Transient lower oesophageal sphincter (LOS) relaxation; $\mathbb{D}$ strain; $\mathbb{Z}$ swallow induced LOS relaxation; $\square$ absent basal LOS pressure; - not interpretable.

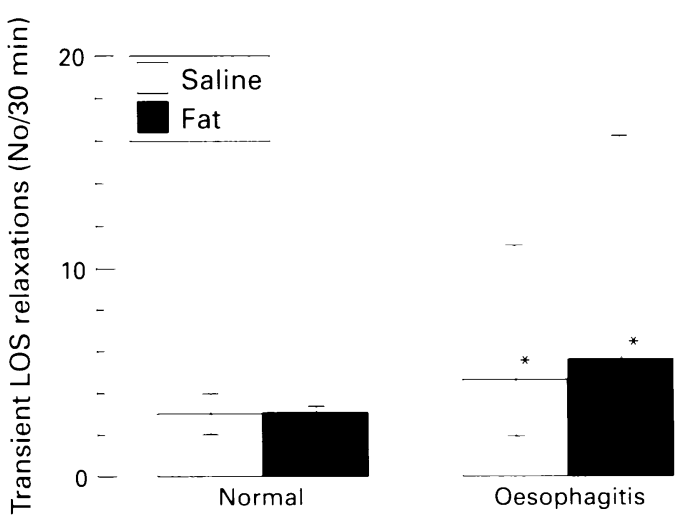

Figure 4: Effect of intraduodenal fat on the rate of transient lower oesophageal sphincter (LOS) relaxations. Data expressed as median (interquartile range), ${ }^{*} p<0.05 \mathrm{v}$ normal subjects. 

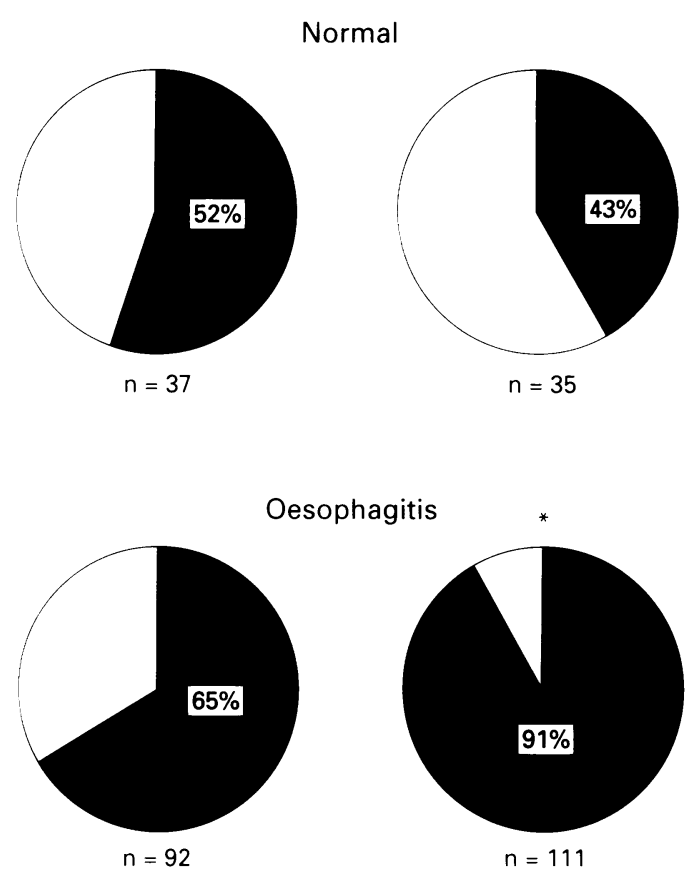

Saline

Figure 5: Effect of intraduodenal fat on the proportion of transient lower oesophageal sphincter relaxations associated with reflux. Transient lower oesophageal sphincter relaxations associated with reflux; $\square$ transient lower oesophageal sphincter relaxations not associated with reflux. ${ }^{*} p<0.05 \mathrm{v}$ saline.

\section{Discussion}

In this study the effects of intraduodenal fat on patterns and mechanisms of reflux have been investigated with a standardised cross over study design. By contrast with the popularly held notion that fat provokes reflux by reducing basal LOS pressure, ${ }^{4}$ we have shown that, at least in resting recumbent patients with reflux oesophagitis, fat provokes reflux by increasing the incidence of reflux during transient LOS relaxations.

Previous studies on the effect of fat on gastro-oesophageal reflux have yielded conflicting findings. Ambulatory oesophageal $\mathrm{pH}$ monitoring studies in normal subjects have found that high fat meals are associated with greater oesophageal acid exposure in the upright posture than are low fat meals. ${ }^{2}$ The effects on the rate of reflux episodes were not reported. Perhaps surprisingly, high fat meals had no effect on oesophageal acid exposure in patients with reflux disease when compared with low fat meals. It was suggested that these findings were explainable on the basis that basal LOS pressure was already abnormally low before the high fat meal in the patients with reflux disease, even though basal LOS pressure in the patients was in most instances above 10 $\mathrm{mm} \mathrm{Hg}$. In a more recent study, three hour postprandial recordings also failed to detect any effect of a high fat meal on oesophageal acid exposure and the rate of acid reflux episodes in either patients with reflux disease or normal subjects. ${ }^{15}$

Our findings of increased reflux in patients with reflux disease but not in normal subjects differ from the earlier results. This disparity might, in part, be the result of the different methods used. Firstly, we measured reflux for only 30 minutes during the duodenal stimulus. This may have been insufficient time to detect an effect on relatively infrequent events in the normal subjects. Secondly, the present study entailed a substantially greater difference in the fat load to the duodenum between the two study days, compared with previous studies. We used virtually $100 \%$ triglyceride compared with no fat at all on the control day. This contrasts with $65 \%$ and $30 \%$ fat on the two study days in the postprandial study ${ }^{15}$ and $61 \%$ and $16 \%$ fat respectively in the ambulatory study. ${ }^{2}$

We hypothesised that fat would increase reflux by increasing the rate of transient LOS relaxations. This was not the case. Rather, fat increased the likelihood of reflux occurring during transient LOS relaxations. The mechanisms underlying this effect are not clear. It is possible that fat induced relaxation of the proximal stomach ${ }^{16}$ leads to increased pooling of liquid in the proximal stomach and thereby a larger reservoir of refluxate. This hypothesis remains to be tested.

As with the previous studies, ${ }^{4}$ we noted a modest but significant fall in basal LOS pressure with intraduodenal fat in the normal subjects. This fall was not to the extent that it would be expected by itself to impair sphincter competence. Previous studies have shown that sphincter competence is preserved provided that basal pressure exceeds as little as $3 \mathrm{~mm}$ $\mathrm{Hg}^{7}{ }^{17}$ Our data do not, however, totally exclude the possibility that fat might aggravate reflux by reducing basal LOS pressure. In subjects with very low basal LOS pressures, a reduction in basal pressure by fat could conceivably reduce basal pressure to below the threshold to maintain competence. Interestingly, fat had no effect on basal LOS pressure in patients with reflux disease. The reason for this remains to be determined. However, by contrast with an earlier suggestion, ${ }^{2}$ it cannot be explained on the basis of lower LOS pressure in the patients with reflux as this was similar in normal subjects.

In summary, instillation of fat directly into the duodenum significantly increases the rate of reflux episodes in patients with reflux disease by increasing the likelihood of reflux occurring during transient LOS relaxations. This effect may contribute to the intolerance of fatty food experienced by these patients.

This study was supported by a project grant from the Australian National Health and Medical Research Council. AI was supported by a Travelling Fellowship from the Royal College of Physicians in Edinburgh. The technical assistance of $\mathrm{Mr}$ Marcus Tippett is gratefully acknowledged.

1 Nebel OT, Fornes MF, Castell DO. Symptomatic gastroesophageal reflux: incidence and precipitating factors. Dig Dis 1976; 21: 953-6.

2 Becker DJ, Sinclair J, Castell DO, Wu WC. A comparison of high and low fat meals on postprandial esophageal acid exposure. Am $\mathcal{F}$ Gastroenterol 1989; 84: 782-6.

3 Nebel OT, Castell DO. Lower esophageal sphincter pressure changes after food ingestion. Gastroenterology 1972; 63: 778-83.

4 Nebel OT, Castell DO. Inhibition of the lower oesophageal sphincter by fat - a mechanism for fatty food intolerance. Gut 1973; 14: 270-4

5 Dent J, Dodds WJ, Friedman RH, et al. Mechanism of gastroesophageal reflux in recumbent asymptomatic subjects. F Clin Invest 1980; 65: 256-67. 
6 Dent J, Holloway RH, Toouli J, Dodds WJ. Mechanisms of lower oesophageal sphincter incompetence in patients
with symptomatic gastroesophageal reflux. Gut 1988; 29: with symptc

7 Dodds W, Dent J, Hogan W, et al. Mechanisms of gastroesophageal reflux in patients with reflux esophagitis. $N$ Engl f Med 1982; 307: 1547-52.

8 Dent J. A new technique for continuous sphincter pressure measurement. Gastroenterology 1976; 71: 263-71.

9 Houghton LA, Read NW, Heddle $R$, et al. Motor activity of the castric antrum, pylorus and duodenum under fasted conditions and after a liquid meal. Gastroenterology 1988; 94: 1276-84.

10 Brener W, Hendrix TR, McHugh PR. Regulation of the gastric emptying of glucose. Gastroenterology 1983; 85: 76-82.

11 Collins PJ, Horowitz M, Cook DJ, Harding PE, Shearman DJ. Gastric emptying in normal subjects - a reproducible technique using a single scintillation camera and computer system. Gut 1983; 24: 1117-25.
12 Heddle R, Dent J, Read NW, et al. Antropyloroduodenal motor responses to intraduodenal lipid infusion in healthy volunteers. Am $\mathcal{F}$ Physiol 1988; 254: G671-9.

13 Heddle R, Collins P, Dent J, et al. Motor mechanism associated with slowing of the gastric emptying of a solid meal by an intraduodenal lipid infusion. $\mathcal{F}$ Gastroenterol Hepatol 1989; 4: 437-47.

14 Holloway RH, Kocyan P, Dent J. Provocation of transient lower esophageal sphincter relaxations by meals in patients wiht symptomatic gastroesophageal reflux. Dig Dis Sci 1991; 36: 1034-9.

15 Mangano M, Picone A, Bianchi PA, Penagini R. High fat meals: do they really affect the competence of the meals: do they really affect the competence of the Motil 1995; 7: 273 .

16 Azpiroz F, Malagelada J-R. Intestinal control of gastric tone Am f Physiol 1985; 249: G501-9.

17 Dent J, Dodds WJ, Hogan WJ, Toouli J. Factors that influence induction of gastroesophageal reflux in normal human subjects. Dig Dis Sci 1988; 33: 270-5. 